\title{
The relationship between health risk and consumption of confectioneries: An instrumental variable approach
}

\author{
Yong Kang Cheah ${ }^{1 *}$, Mohd Azahadi ${ }^{2}$, Noor Safiza Mohamad Nor ${ }^{3}$, Siew Nooi \\ Phang $^{4}$ \& Noor Hazilah Abd Manaf
}

\begin{abstract}
${ }^{1}$ School of Economics, Finance and Banking, College of Business, Universiti Utara Malaysia, 06010 UUM Sintok, Kedah Darul Aman, Malaysia; ${ }^{2}$ Research Planning and Policy Division, National Institute of Health, No. 1, Jn Setia Murni U13/52, Seksyen U13, 40170 Shah Alam, Selangor, Malaysia; ${ }^{3}$ Centre for Nutrition Epidemiology Research, Institute for Public Health, No. 1, Jn Setia Murni U13/52, Seksyen U13, 40170 Shah Alam, Selangor, Malaysia; ${ }^{4}$ School of Government, College of Law, Government and International Studies, Universiti Utara Malaysia, 06010 UUM Sintok, Kedah Darul Aman, Malaysia; ${ }^{\mathbf{5}}$ Department of Business Administration, Faculty of Economics and Management Sciences, International Islamic University Malaysia, 50728 Kuala Lumpur, Malaysia.
\end{abstract}

\begin{abstract}
Introduction: Consumption of confectioneries is a determinant of health risk. However, how health risk determines the intake of confectioneries remains unclear. The objective is to examine how waist circumference (WC) as a measurement of health risk influences the consumption of confectioneries among adults. The research question is that do high-risk people consume more confectioneries than low-risk people? Methods: A quantitative research design with a focus on establishing a correlation between the measurement of health risk and consumption of confectioneries was adopted. Secondary analysis of a nationally representative cross-sectional data was used. The population of interest was the Malaysian population, regardless of being obese or non-obese. Analyses stratified by body mass index (BMI) or WC were not conducted. An instrumental variable (IV) approach was used to estimate the regression of consumption of confectioneries. BMI was used as an IV for WC. In the first stage, we regressed WC on all exogenous variables, including BMI. Then, we replaced the original values of $\mathrm{WC}$ with the fitted values of WC. Results: BMI was an appropriate IV for WC. An additional $\mathrm{cm}$ of WC was associated with a 0.022 unit of reduction in the serving of confectioneries per week. The negative relationship between WC and consumption of confectioneries indicated that adults who had high health risk consumed lesser confectioneries than adults who had low health risk. Conclusion: Drawing from the IV regression results, the present study highlighted that people with high health risk, rather than people with low health risk, were less likely to consume confectioneries.
\end{abstract}

Keywords: Body mass index, confectionery, health risk, obesity, waist circumference

\section{INTRODUCTION}

Waist circumference (WC) is considered a measurement of health risk. Health risk is defined as an individual's probability of developing a disease. Large WC is related to various non-communicable diseases

\footnotetext{
*Corresponding author: Yong Kang Cheah

Postal address: School of Economics, Finance and Banking, College of Business,

Universiti Utara Malaysia, 06010 UUM Sintok, Kedah Darul Aman, Malaysia.

Tel: (6)(04)9286870; E-mail: cheahykang@gmail.com

doi: https://doi.org/10.31246/mjn-2019-0076
} 
(NCDs), most notably cardiovascular disease, stroke and diabetes, accounting for greater mortalities than small WC (WHO, 2018). Individuals who are in the upper quantile of WC have about $137-216 \%$ higher odds of developing hypercholesterolemia, hypertension and diabetes compared with individuals who are in the lower quantile of WC (Zhu et al., 2002). An increase of $1 \mathrm{~cm}$ in WC raises the odds of being diagnosed with high triglycerides and metabolic syndrome by 6-7\% (Janssen, Katzmarzyk $\&$ Ross, 2004). Men and women who have large WC are two times more likely to suffer from colon cancer than their counterparts having small WC (Moore et al., 2004). It is apparent that large WC indicates higher health risk, while small WC denotes lower health risk.

The increase in the prevalence of NCDs has become a serious global public health concern, notably in developing countries, including Malaysia (Lum, 2018; WHO, 2018). From 2006 to 2015, the prevalences of obesity, diabetes and hypercholesterolemia in Malaysia increased from $14.0 \%, 11.5 \%$ and $20.7 \%$ to $17.7 \%, 17.5 \%$ and $47.7 \%$, respectively (IPH, 2008; Wan Mohamud et al., 2011; IPH, 2015). There are numerous factors that elevate health risk or increase WC. One of the factors is the excessive consumption of added sugar, including confectioneries (Hu, 2013; Stem et al., 2017). Added sugar is sugar that is added to foods and beverages, whilst confectionery is a type of food that consists of added sugar. Therefore, the greater the consumption of confectioneries, the greater the intake of added sugar. There is evidence suggesting that an additional serving of added sugar per day increases WC by $1 \mathrm{~cm}$ (Stem et al., 2017). On average, a Malaysian adult consumes about 5.2 servings of confectioneries per week (IPH, 2014). This amount is significantly high, especially given that carbohydrate-rich foods are the staples of the Malaysian people.
Although the effects of added sugar consumption on WC have been welldocumented, how WC as a measurement of health risk determines confectioneries consumption behaviour is unclear. A research question arises: are high-risk people or people with large WC more likely to consume confectioneries than low-risk people or people with small WC? Having a better understanding of confectioneries consumption behaviour among people is important for policy makers if the goal is to lower the risk of disease via a reduction in the consumption of confectioneries. If highrisk people, rather than low-risk people, consume less confectioneries, then anti-confectioneries policy that focuses mainly on high-risk people may be less optimal.

In general, WC can influence confectioneries consumption in two different ways. Firstly, people with high risk of disease, i.e., those who have large $\mathrm{WC}$, tend to have a higher rate of time preference, that is that they are more present oriented than people with low risk of disease, i.e., those who have small WC (Komlos, Smith \& Bogin, 2004; Smith, Bogin \& Bishai, 2005). Since consumption of confectioneries is an unhealthy behaviour, high-risk people are hypothesised to consume more confectioneries than low-risk people. This is our first hypothesis. Secondly, high-risk people are more aware of various diseases compared with low-risk people, and consequently are less likely to consume confectioneries (Lin et al., 2016; Park et al., 2016). Hence, a negative relationship between having a large WC and consumption of confectioneries is hypothesised. This is our second hypothesis. With that, the objective of the present study is to examine the influence of $\mathrm{WC}$, i.e., a measurement of health risk, on the consumption of confectioneries.

The relationship between health risk and intake of added sugar has been 
examined in previous studies (Rehm et al., 2008; Bleich \& Wang, 2011; Zytnick et al., 2015; Park et al., 2016; Pollard et al., 2016; Xu, Park \& Siegel, 2018). Although previous findings are interesting, they have some limitations. Firstly, body mass index (BMI) was used to measure health risk. This may result in measurement error as BMI cannot measure fat, body image and health condition accurately. As numerous studies have indicated, BMI is not a good measure for health risk because it does not differentiate between weight from fat and weight from muscle and bone (Burkhauser \& Cawley, 2008; Kinge, 2017). This means that muscular people or people with a large bone structure, but having low body fat can be miscategorised as having high risk if their BMI is more than $29 \mathrm{~kg} /$ $\mathrm{m}^{2}$. For instance, O'Neill (2015) found that nearly $50 \%$ of high-risk women were misclassified as being low-risk, if BMI was used. In addition, Kragelund \& Omland (2005), Yusuf et al. (2005) and Bozeman et al. (2012) pointed out that BMI was a weaker predictor of illnesses as compared with other measures, such as WC and waist-to-hip ratio. Secondly, even if BMI is a good measure for health risk, it causes simultaneity issue when it is included as an independent variable in the regression for added sugar intake. Since excessive consumption of added sugar can increase body weight, there is a two-way causation between added sugar consumption and BMI. Thus, it can be concluded that BMI is an endogenous variable, which can cause endogeneity problem, that is, a problem that leads to biased and inconsistent estimates if the regressions are not estimated using an instrumental variable (IV) approach.

Owing to these weaknesses, the present study attempts to contribute to the literature in several ways. Firstly, unlike previous studies, the interest of this study is in a rapidly-growing developing country like Malaysia, with a high prevalence of health risk and where empirical studies related to health risk and added sugar consumption are lacking. Moreover, the obesity rate in Malaysia is quite high $(17.7 \%)$. Hence, it can be useful for policy makers to examine how food consumption behaviour is affected by health risk. Furthermore, as pointed out by Kleiman, Ng \& Popkin (2012), the majority of the sales of sugary foods across the globe is in developing countries, making the prevalence of diseases worse-off. In this context, it justifies paying more attention to a developing country than a developed country.

Secondly, the present study replaces BMI with WC and examines how it affects confectioneries consumption. WC has been proven to be a better measure and predictor of health risk than BMI (Kragelund \& Omland, 2005; Yusuf et al., 2005; Bozeman et al., 2012; Zhu et al., 2014). By using WC, low-risk people are unlikely to be misclassified as highrisk people and vice versa (O'Neill, 2015). It is well-documented that where fat is located in a person's body is significant. Fat accumulated in the abdomen is more dangerous than in the hips or in other parts of the body (Burkhauser \& Cawley, 2008). Hence, measurement error can be avoided if WC is used.

Thirdly, although WC is better than BMI, WC is also an endogenous variable due to simultaneity. Hence, in order to overcome the endogeneity issue, IV approach is used to estimate the regression. A quantitative research method with a focus on IV regression is the design of the present study and is considered as the uniqueness of this research. Our estimated results will be unbiased and consistent, thereby able to provide better statistical inferences. If our model is estimated using nonIV methods, such as ordinary least square (OLS), imprecise and biased estimates will be obtained because of the two-way causal relationship between confectioneries consumption and WC. Therefore, it will lead to wrong conclusions and provide policy 
makers with inaccurate information. Using an appropriate IV regression can ensure that this problem will not occur, especially when IV is correctly identified.

\section{MATERIALS AND METHODS}

\section{Data}

Secondary data from the Malaysian Adult Nutrition Survey (MANS) 2014 were used in the present study (IPH, 2014). It was a nationwide survey conducted by the Ministry of Health Malaysia. A multi-stage random sampling was used. In the first stage, the entire country was divided into several enumeration blocks (EBs), i.e., geographical areas with boundaries. Overall, there were about 75,000 EBs. Approximately 49,000 were in urban areas and 26,000 in rural areas. EBs were selected in accordance with the population size of each state. A total of 187 urban EBs and 150 rural EBs were selected. In the second stage, living quarters (LQs) in each EB were randomly selected. Each EB consisted of 80-120 LQs, and each LQ comprised of 500-600 in population. A total of twelve LQs were selected from each EB. In the third stage, individuals aged 18-59 years and who resided in the selected LQs were randomly selected. The exclusion criteria were those who were pregnant or breastfeeding, as well as those who followed a special diet. Since the scope of the present study was the entire Malaysian population, regardless obese or non-obese, and analyses were not stratified by BMI or WC, MANS 2014 was appropriate. Additional information about the sampling are provided elsewhere (IPH, 2014).

Multilingual structured questionnaires were used by trained staffs to conduct face-to-face interviews. These were questions in the questionnaire of the MANS 2014. Signed consent forms were taken from every respondent. A total of 3,000 respondents completed the questionnaire. However, due to missing information, only 2,696 were used for analyses. Despite some observations being deleted, the sample was still nationally representative. Ethical approval of MANS 2014 was given by the Medical Research and Ethics Committee, Ministry of Health Malaysia (NMRR-12-815-13100).

\section{Measurements}

The dependent variable was the consumption of confectioneries. The independent variables were WC, age, income, education, gender, marital status, ethnicity, employment status and household location. BMI was used as an IV. Confectioneries referred to sugar added foods such as cakes, icecream and snacks. Consumption of confectioneries is the total servings of confectioneries consumed by the respondents in a week. It was obtained by asking the respondents 'Normally, how many days in a week do you take confectionery?' and 'Usually on the day you eat confectionery, how many servings do you take?'. Since face-to-face interview was conducted, respondents were provided with detailed explanations. The interviewers ensured that the respondents fully understood the definition of confectionery. Consumption of sugar-sweetened beverages, such as soft drink, sports drink and energy drink was often examined in previous studies (Park et al., 2016; Rehm et al., 2008; Bleich \& Wang, 2011; Zytnick et al., 2015; Pollard et al., 2016; Xu et al., 2018). Different from past researches, consumption of confectioneries was analysed in this study because it had not been examined in great detail and is highly linked to obesity-related illnesses (Naughton, McCarthy \& McCarthy, 2017).

Demographic variables were selected in light of the findings of previous studies (Park et al., 2016; Rehm et al., 2008; Bleich \& Wang, 2011; Friis et al., 2014; Zytnick et al., 2015; Pollard et al., 2016; Xu et al., 2018; Cheah et al., 2019a). Previous studies found 
that older individuals were less likely to consume added sugar than younger individuals because older individuals were more concerned about their health (Rehm et al., 2008; Park et al., 2016; $\mathrm{Xu}$ et al., 2018). Consumption of added sugar varied across income as high income people tended to have better health awareness (Rehm et al., 2008; Bleich \& Wang, 2011). Men were more likely to consume added sugar relative to women because they have a higher tendency to adopt an unhealthy lifestyle (Bleich \& Wang, 2011; Friis et al., 2014; Zytnick et al., 2015; Pollard et al., 2016; $\mathrm{Xu}$ et al., 2018). Being married reduced the consumption of added sugar (Xu et al., 2018) and this was because of an increase in household commitment. Owing to cultural and religious factors, there was an ethnic variation in health behaviour (Cheah et al., 2019b; Cheah et al., 2020). Relative to unemployed individuals, employed individuals consumed more added sugar as they had a better financial capability (Cheah et al., 2019a). Given the geographical differences in the supply of foods, urban and rural dwellers displayed different odds of consuming added-sugar (Park et al., 2016; Cheah et al., 2019a). Given these findings, we expected that demographic factors could affect the consumption of confectioneries.

During the survey, the respondents' height [meter $(\mathrm{m})]$ and weight [kilogram (kg)] were measured using SECA Stadiometer 217 and Tanita Personal Scale HD 319. These information were then used to calculate BMI $\left(\mathrm{kg} / \mathrm{m}^{2}\right)$. In addition, SECA 201 tape was used to measure the respondents' $\mathrm{WC}$ in $\mathrm{cm}$. BMI and WC were formatted as continuous variables, instead of categorical variables, to facilitate IV regression. Nevertheless, in an effort to understand how many percent of the respondents were obese or non-obese, we categorised BMI into obese (BMI $25 \mathrm{~kg} / \mathrm{m}^{2}$ ) and nonobese (BMI $<25 \mathrm{~kg} / \mathrm{m}^{2}$ ) categories for descriptive statistics purpose.

\section{Research design}

The present study used a quantitative research design, particularly the correlational research design, to understand the correlation between the measurement of health risk and consumption of confectioneries. Quantitative research is a method of collecting quantifiable data and carrying out statistical tests, whilst correlational research is a method of identifying the association between two variables. In the present study, secondary analysis of survey data was conducted. The survey gathered measurable information on health risk and confectioneries consumption. The quantitative research approach was suitable for the present study because it could establish a relationship between the measurement of health risk and consumption of confectioneries by using available survey data. In addition, the present study attempted to deal with statistical issue, thus quantitative method was considered appropriate.

WC was an endogenous variable resulted from simultaneity as it could be jointly determined with the consumption of confectioneries. While WC may affect the decisions of people in the amount of confectioneries to consume, indeed, consuming too much confectioneries may increase WC. As such, using OLS or other non-IV methods to estimate the regression of consumption of confectioneries, that included $\mathrm{WC}$ as an independent variable, was likely to generate biased and inconsistent results. This was the problem of endogeneity. In order to overcome this problem, IV approach must be adopted.

Kinge (2017) used family members' WC as an IV for WC. However, because of data limitation, we did not have information on this variable. Instead, we used BMI as an IV for WC given that it satisfied these two main criteria (Wooldridge, 2013; Mehta, 2015). Firstly, BMI was highly correlated with WC. The covariance between these two variables 
was not zero. People with high BMI was likely to have large WC. As pointed out by Bozeman et al. (2012), BMI was able to predict WC. Secondly, we assumed that WC, instead of BMI, had a direct effect on the consumption of confectioneries, because WC was a better measurement of health risk. People who had high BMI did not necessarily have high body fat or poor health conditions. They may be muscular or have a larger bone structure and lean body mass.

Two stage least square (2SLS), i.e., a method of IV, was used to estimate the regression. Since BMI appeared in the regression of $\mathrm{WC}$, but not the others, the regression of consumption of confectioneries could be identified. In the first stage, we regressed WC on all the exogenous variables and BMI. This regression was known as a reduced form equation. The fitted values of WC were then used in the second stage. They replaced the original values of WC. Moreover, we used gender as an additional IV for WC in an effort to compare whether BMI was a better IV than demographic variables. We expected that gender would be highly correlated with WC. In the second stage, we regressed the consumption of confectioneries on all independent variables and the fitted values of WC. This regression was a structural equation, which was the model of primary interest of the present study. For comparison purpose, we also estimated the main regression using OLS. Because the fitted values of WC had lesser variations and were highly correlated with other exogenous variables, the standard errors of the IV estimates tended to be larger than those of the OLS estimates. Hence, robust standard errors of the IV estimates were calculated.

In spite of the assumption stating that BMI was an appropriate IV, we conducted a statistical test to confirm if this was true. We used OLS to estimate a multiple regression of $\mathrm{WC}$ on $\mathrm{BMI}$ and other exogenous variables. If the estimate of BMI was significant, BMI was considered to be an appropriate IV and the equation for the consumption of confectioneries could be identified. IV approach had been previously used to study the relationship between obesity and medical costs (Cawley \& Meyerhoefer, 2012), and demand for cigarettes (Kenkel, Schmeiser \& Urban, 2014).

\section{RESULTS}

The majority of the respondents were aged 30-39 years (27.3\%), followed by those aged $\leq 29$ years $(26.2 \%), 40-49$ years $(26.0 \%)$ and $\geq 50$ years $(20.6 \%)$. Approximately 52.3\%, 21.3\%, 9.9\%, $7.1 \%$ and $9.6 \%$ of the respondents had a monthly income of $\leq$ Ringgit Malaysia (RM) 999, RM1000-1999, RM20002999, RM3000-3999 and $\geq$ RM4000, respectively. A large proportion of the respondents had secondary level education $(64.3 \%)$, followed by those who had primary level (20.8\%), tertiary level $(10.1 \%)$ and no formal education $(4.8 \%)$. Slightly more than half of the respondents were females (53.5\%). Nearly two-third of the respondents were married $(68.8 \%)$, while only $24.7 \%$ and $6.5 \%$ were single and widowed/divorced, respectively. The ethnic breakdown consisted of $72.4 \%$ Bumiputera, $17.1 \%$ Chinese, $4.5 \%$ Indians and $6.1 \%$ individuals from other ethnic backgrounds. Of the total respondents, the majority were employed $(74.3 \%)$ and resided in urban areas $(52.7 \%)$ (Table 1$)$.

On average, the respondents consumed about 4.190 servings of confectioneries (e.g. cakes, ice-cream, snacks etc.) per week. This amount of serving was slightly lesser than the amount reported in MANS 2014, i.e., 5.2 servings, because of the different calculation formulas employed (IPH, 2014). Our calculation included the respondents who reported zero intake of confectioneries, thus the mean value of confectioneries intake (i.e., 
Table 1. Variables and correlates of BMI and other exogenous variables to WC $(\mathrm{N}=2696)$

\begin{tabular}{|c|c|c|c|c|c|}
\hline Variables & $\begin{array}{l}\text { Mean } \\
\text { (standard } \\
\text { deviation) }\end{array}$ & $\begin{array}{l}\text { Frequency } \\
\text { (percentage) }\end{array}$ & Estimates & $\begin{array}{l}\text { Standard } \\
\text { errors }\end{array}$ & p-value \\
\hline Constant & - & - & 44.682 & 1.009 & $<0.001$ \\
\hline Confectioneries & $4.19(5.84)$ & - & - & - & - \\
\hline WC (cm) & $84.58(13.21)$ & - & - & - & - \\
\hline BMI $\left(\mathrm{kg} / \mathrm{m}^{2}\right)$ & 25.99 (6.68) & - & 1.470 & 0.025 & $<0.001$ \\
\hline \multicolumn{6}{|l|}{ BMI } \\
\hline Obese & - & 1394 (51.7) & - & - & - \\
\hline Non-obese & - & 1302 (48.3) & - & - & - \\
\hline \multicolumn{6}{|l|}{ Age } \\
\hline$\leq 29$ years & - & 707 (26.2) & - & - & - \\
\hline 30-39 years & - & $737(27.3)$ & 0.029 & 0.519 & 0.956 \\
\hline 40-49 years & - & $700(26.0)$ & -0.311 & 0.553 & 0.574 \\
\hline$\geq 50$ years & - & $554(20.6)$ & 0.709 & 0.599 & 0.237 \\
\hline \multicolumn{6}{|l|}{ Income } \\
\hline$\leq$ RM999 & - & 1409 (52.3) & - & - & - \\
\hline RM1000-1999 & - & $573(21.3)$ & 0.084 & 0.487 & 0.862 \\
\hline RM2000-2999 & - & $266(9.9)$ & 0.835 & 0.652 & 0.200 \\
\hline RM3000-3999 & - & $190(7.1)$ & 0.182 & 0.748 & 0.808 \\
\hline$\geq \mathrm{RM} 4000$ & - & $258(9.6)$ & -0.008 & 0.742 & 0.991 \\
\hline \multicolumn{6}{|l|}{ Education } \\
\hline Tertiary & - & $272(10.1)$ & - & - & - \\
\hline Secondary & - & 1734 (64.3) & -0.508 & 0.650 & 0.434 \\
\hline Primary & - & $560(20.8)$ & 0.080 & 0.776 & 0.918 \\
\hline No formal & - & $130(4.8)$ & 0.847 & 1.045 & 0.417 \\
\hline \multicolumn{6}{|l|}{ Gender } \\
\hline Male & - & 1255 (46.6) & 1.833 & 0.376 & $<0.001$ \\
\hline Female & - & 1441 (53.5) & - & - & - \\
\hline \multicolumn{6}{|l|}{ Marital status } \\
\hline Married & - & 1855 (68.8) & 0.468 & 0.486 & 0.335 \\
\hline Single & - & $665(24.7)$ & - & - & - \\
\hline Widow/divorce & - & $176(6.5)$ & 1.235 & 0.825 & 0.134 \\
\hline \multicolumn{6}{|l|}{ Ethnicity } \\
\hline Bumiputera & - & 1953 (72.4) & - & - & - \\
\hline Chinese & - & $460(17.1)$ & 0.808 & 0.493 & 0.102 \\
\hline Indian & - & $120(4.5)$ & 2.046 & 0.839 & 0.015 \\
\hline Others & - & $163(6.1)$ & 0.153 & 0.738 & 0.836 \\
\hline \multicolumn{6}{|l|}{ Employment } \\
\hline Employed & - & 2003 (74.3) & -0.161 & 0.460 & 0.726 \\
\hline Unemployed & - & $693(25.7)$ & - & - & - \\
\hline \multicolumn{6}{|l|}{ Location } \\
\hline Urban & - & 1420 (52.7) & 0.789 & 0.375 & 0.035 \\
\hline Rural & - & 1276 (47.3) & - & - & - \\
\hline
\end{tabular}

Source: MANS 2014 (IPH, 2014) 
unconditional mean) was somewhat smaller. The average units for WC and BMI of the total respondents were $84.6 \mathrm{~cm}$ and $26.0 \mathrm{~kg} / \mathrm{m}^{2}$, respectively. Of all the respondents, $51.7 \%$ were obese and $48.3 \%$ were non-obese. BMI seemed to be significantly associated with WC, and so was gender. Holding other factors constant, on average, an increase of one unit of BMI increased WC by $1.5 \mathrm{~cm}$, and males' WC was $1.8 \mathrm{~cm}$ larger than females' WC.

Using BMI as an IV, the results of 2SLS regression showed that an additional $\mathrm{cm}$ of WC was associated with a 0.022 unit reduction in the serving of confectioneries per week, if the values of other variables were held fixed. This meant that for every $20 \mathrm{~cm}$ increase in WC, the weekly intake of confectioneries was lower by 0.500 serving. These results supported our second hypothesis that having a large WC was negatively related to the consumption of confectioneries. However, when gender was used as an $\mathrm{IV}$, the relationship between $\mathrm{WC}$ and confectioneries consumption became insignificant, implying that demographic variables may not be a better IV for WC compared with BMI. Considering the OLS estimates, for every one unit increase in $\mathrm{WC}$, the consumption of confectioneries reduced by only 0.018 serving (Table 2).

\section{DISCUSSION}

Considering the two-way causal relationship between health risk and confectioneries consumption, the present study examined the influence of WC, i.e., a measurement of health risk, on consumption of confectioneries among adults. Owing to the fact that WC was an endogenous variable, IV approach was utilised to estimate the regression of confectioneries consumption. BMI was used as an IV for WC. Our findings suggested that BMI was an appropriate IV for WC as there was a significant association between these two variables, although it may not be the best IV. In addition, our findings showed that WC was negatively associated with the consumption of confectioneries, which indicated that adults who had high risk of disease consumed lesser added sugar than adults who had low risk of disease. However, we were unable to identify whether high-risk people consumed more or lesser fat and energy-dense foods than low-risk people because of data limitation. Moreover, the IV estimate of WC was found to be larger and more statistically significant than the OLS estimate. This implied that if non-IV method was used, the effect of WC on confectioneries consumption would be underestimated and may consequently be neglected by researchers and policy makers. The outcome could result in an inappropriate conclusion with dire consequences on public policy development.

A similar relationship between BMI and WC was evidenced in previous studies (Chinedu et al., 2013; Gierach et al., 2014), particularly in studies that used various statistical approaches and found a strong positive correlation between BMI and WC. Given that the effect of WC on confectioneries consumption had not been examined in previous studies, our literature review was based on studies pertaining to the relationship between BMI and consumption of added sugar. Similar to WC, high-risk people referred to those with high BMI, while low-risk people referred to those with low BMI. The relationship between BMI and consumption of added sugar found in previous studies appeared to be mixed. Using data from the National Health Interview Survey, Park et al. (2016) found that high-risk men were less likely to consume added sugar compared to low-risk men. They claimed that people who had high risk had a higher tendency to reduce their sugar intake in an effort to reduce their risks of suffering from diseases than their low-risk counterparts. Similar findings were evidenced by Zytnick et al. (2015), 
Table 2. Correlates of WC and demographic factors to consumption of confectioneries, $N=2696$

\begin{tabular}{|c|c|c|c|}
\hline \multirow{2}{*}{$\begin{array}{l}\text { Variables } \\
\text { Constant }\end{array}$} & OLS & $2 S L S^{a}$ & $2 S L S^{b}$ \\
\hline & $\begin{array}{l}5.934^{*} \\
(0.861)\end{array}$ & $\begin{array}{l}6.313^{*} \\
(0.909)\end{array}$ & $\begin{array}{l}20.764^{*} \\
(10.013)\end{array}$ \\
\hline $\mathrm{WC}(\mathrm{cm})$ & $\begin{array}{l}-0.018^{*} \\
(0.008)\end{array}$ & $\begin{array}{l}-0.022^{*} \\
(0.009)\end{array}$ & $\begin{array}{l}-0.198 \\
(0.121)\end{array}$ \\
\hline \multicolumn{4}{|l|}{ Age } \\
\hline$\leq 29$ years & - & - & - \\
\hline 30-39 years & $\begin{array}{l}0.094 \\
(0.341)\end{array}$ & $\begin{array}{l}0.095 \\
(0.378)\end{array}$ & $\begin{array}{l}0.158 \\
(0.403)\end{array}$ \\
\hline 40-49 years & $\begin{array}{l}-0.146 \\
(0.363)\end{array}$ & $\begin{array}{l}-0.150 \\
(0.429)\end{array}$ & $\begin{array}{l}-0.327 \\
(0.457)\end{array}$ \\
\hline$\geq 50$ years & $\begin{array}{l}-0.368 \\
(0.394)\end{array}$ & $\begin{array}{l}-0.361 \\
(0.405)\end{array}$ & $\begin{array}{l}-0.206 \\
(0.449)\end{array}$ \\
\hline \multicolumn{4}{|l|}{ Income } \\
\hline$\leq$ RM999 & - & - & - \\
\hline RM1000-1999 & $\begin{array}{l}0.371 \\
(0.319)\end{array}$ & $\begin{array}{l}0.377 \\
(0.336)\end{array}$ & $\begin{array}{l}0.418 \\
(0.366)\end{array}$ \\
\hline RM2000-2999 & $\begin{array}{l}-0.442 \\
(0.428)\end{array}$ & $\begin{array}{l}-0.440 \\
(0.402)\end{array}$ & $\begin{array}{l}-0.336 \\
(0.440)\end{array}$ \\
\hline RM3000-3999 & $\begin{array}{l}0.333 \\
(0.491)\end{array}$ & $\begin{array}{l}0.341 \\
(0.578)\end{array}$ & $\begin{array}{l}0.561 \\
(0.642)\end{array}$ \\
\hline$\geq \mathrm{RM} 4000$ & $\begin{array}{l}0.555 \\
(0.487)\end{array}$ & $\begin{array}{l}0.557 \\
(0.478)\end{array}$ & $\begin{array}{l}0.644 \\
(0.523)\end{array}$ \\
\hline \multicolumn{4}{|l|}{ Education } \\
\hline Tertiary & - & - & - \\
\hline Secondary & $\begin{array}{l}0.464 \\
(0.426)\end{array}$ & $\begin{array}{l}0.461 \\
(0.398)\end{array}$ & $\begin{array}{l}0.425 \\
(0.429)\end{array}$ \\
\hline Primary & $\begin{array}{l}-0.492 \\
(0.509)\end{array}$ & $\begin{array}{l}-0.487 \\
(0.449)\end{array}$ & $\begin{array}{l}-0.392 \\
(0.498)\end{array}$ \\
\hline No formal & $\begin{array}{l}-1.118 \\
(0.686)\end{array}$ & $\begin{array}{l}-1.116 \\
(0.583)\end{array}$ & $\begin{array}{l}-0.991 \\
(0.648)\end{array}$ \\
\hline \multicolumn{4}{|l|}{ Gender } \\
\hline Male & $\begin{array}{l}-0.393 \\
(0.247)\end{array}$ & $\begin{array}{l}-0.382 \\
(0.246)\end{array}$ & - \\
\hline Female & - & - & - \\
\hline \multicolumn{4}{|l|}{ Marital status } \\
\hline Married & $\begin{array}{l}-0.127 \\
(0.319)\end{array}$ & $\begin{array}{l}-0.118 \\
(0.369)\end{array}$ & $\begin{array}{l}0.178 \\
(0.405)\end{array}$ \\
\hline Single & - & - & - \\
\hline Widow/divorce & $\begin{array}{l}-0.083 \\
(0.542)\end{array}$ & $\begin{array}{l}-0.074 \\
(0.482)\end{array}$ & $\begin{array}{l}0.332 \\
(0.527)\end{array}$ \\
\hline
\end{tabular}


Table 2. Correlates of WC and demographic factors to consumption of confectioneries, N=2696 [cont'd]

\begin{tabular}{llll}
\hline Variables & OLS & $2 S L S^{a}$ & $2 S L S^{b}$ \\
\hline Ethnicity & & & - \\
Bumiputera & - & - & $-2.299^{*}$ \\
& & & $(0.354)$ \\
Chinese & $-2.372^{*}$ & $-2.372^{*}$ & $-1.337^{*}$ \\
& $(0.324)$ & $(0.315)$ & $(0.594)$ \\
Indian & $-1.757^{*}$ & $-1.749^{*}$ & $-1.315^{*}$ \\
Others & $(0.551)$ & $(0.423)$ & $(0.627)$ \\
& $-0.975^{*}$ & -0.987 & 0.446 \\
Employment & $(0.484)$ & $(0.541)$ & $(0.320)$ \\
Employed & 0.573 & & - \\
Unemployed & $(0.302)$ & 0.570 & \\
Location & - & $(0.305)$ & 0.083 \\
Urban & & - & $(0.271)$ \\
Rural & -0.043 & -0.036 & - \\
\hline
\end{tabular}

Note: aBMI is used as an IV. bgender is used as an IV. Standard errors in parentheses ${ }^{*} p<0.05$

Source: MANS 2014 (IPH, 2014)

who used a different dataset. Their findings showed that high-risk adults consumed lesser sports drinks than lowrisk adults. On the other hand, Pollard et al. (2016), who investigated the intake of added sugar among Australians, found that high-risk women consumed more added sugar than low-risk women. They argued that the reverse causation between health risk and added sugar consumption was the reason. $\mathrm{Xu}$ et al. (2018) in examining the consumption of added sugar among adults with and without diabetes, also found that highrisk adults were more likely to consume added sugar than low-risk adults. Our findings confirmed our second hypothesis that high-risk people were more likely to take care of their health by avoiding confectioneries, as well as the findings of Park et al. (2016) and Zytnick et al. (2015) that being high-risk was inversely related to added sugar intake. Since Park et al. (2016) and Zytnick et al. (2015) used logistic regressions, the magnitude of WC evidenced in the present study could not be directly compared with their estimates.

Because individuals who have an unhealthy body weight usually have a large $\mathrm{WC}$, except those with high lean body mass, there exists a significant positive relationship between $\mathrm{WC}$ and BMI. Even though WC is a more accurate determinant of the consumption of confectioneries compared with BMI as it predicts obesity-related diseases and mortality better than BMI (Kragelund \& Omland, 2005; Yusuf et al., 2005; Bozeman et al., 2012; Zhu et al., 2014), WC and BMI are closely related. It appears, therefore, that BMI is an appropriate IV for WC. Given that consumption of confectioneries is an unhealthy behaviour, people often believe that high-risk people are associated with high consumption of confectioneries. However, findings of the present study 
indicated that this was not necessarily the case. In fact, high-risk people are more aware of their health than low-risk people, and thus have a lower likelihood of consuming confectioneries (Lin et al., 2016; Park et al., 2016).

Given the findings of the present study, we suggest that an intervention measure directed towards reducing the consumption of confectioneries among low-risk people or people with small WC should be adopted and emphasised in order to prevent further increases in the prevalence of diseases. More attention should be paid to this group of population than highrisk people or people with large WC. Unfortunately, analysis stratified by WC was not conducted in the present study, therefore we were unable to identify factors other than risk that determined confectioneries consumption among high- and low-risk people. This could be a direction for future research. Also, the cost-effectiveness of policies was not analysed in our study, thus we avoided providing any unverified extrapolations to possible anti-confectioneries policies.

While the present study had significantly illustrated the effect of WC on consumption of confectioneries, it had some limitations. For instance, all the information, except for BMI and WC, were self-reported by the respondents. Hence, minor reporting errors may have existed as high-risk people may have underestimated or underreported their consumption of confectioneries. However, this error was not as serious as what had been found by Ali Zainuddin et al. (2019). The authors calculated the respondents' energy intake-basal metabolic rate ratio and found high prevalence of underreporting of energy intake in MANS 2014. This should not be an issue in the present study because in MANS 2014, the questions used to obtain data on confectioneries intake were not related to the questions used to calculate energy intake. This meant that even though the information on energy intake lacked reliability, the data on confectioneries consumption were still reliable and useful for research.

Another limitation was that the data on confectioneries consumption were not obtained from very thorough dietary assessment techniques, such as 24-hour diet recall, and there was no information on total sugar intake per respondent. Next, given that cross-sectional data were used, the causality between WC and confectioneries intake could not be well identified. Finally, some people consumed confectioneries infrequently, therefore, asking if a respondent consumed confectioneries weekly may have caused a lack of variation in the data. Notwithstanding, future research with data availability would facilitate in a better IV for WC, such as WC of the respondents' siblings or parents. In addition, other types of measurement of health risk, such as waist-to-hip ratio and body fat percentage could be considered in the analysis. Moreover, data with a larger sample size, if available, should be utilised in order to generate more efficient estimates.

\section{CONCLUSION}

The present study found that BMI was positively associated with WC, indicating that obese people were likely to have large WC. In addition, there was a strong evidence suggesting that individuals who had large WC were less likely to consume confectioneries compared to individuals who had small WC. This implied that high-risk people were more aware of their health than low-risk people, and consequently had a lower tendency to consume confectioneries. In terms of policy implications, an intervention strategy directed towards reducing the intake of confectioneries among low-risk people or people who have small WC may yield promising results. Policy makers are suggested to make a concerted effort to improve health awareness among this group of population by providing 
them with adequate knowledge about the negative consequences of excessive consumption of confectioneries.

\section{Acknowledgement}

The authors would like to thank the Director General of Health, Malaysia for his permission to use the data from the Malaysian Adult Nutrition Survey (MANS) 2014 and to publish this paper. The authors would also like to thank Jianfei Cao for his feedback and comments. This research received funding from the Fundamental Research Grant Scheme (FRGS) (KOD SO 14218), which is sponsored by the Ministry of Education Malaysia.

\section{Authors' contributions}

CYK, conceptualised the study, contributed in the funding acquisition, methodology, validation, formal analysis, investigation, drafting of original manuscript, reviewing and editing of the manuscript, visualisation and supervision of the study; MA, contributed in the methodology and validation of the study; NSMN, contributed in the methodology and validation of the study; PSN, contributed in the drafting, reviewing and editing of the manuscript; NHAM, contributed in the reviewing and editing of the manuscript.

\section{Conflict of interest}

The authors have no competing interests to declare.

\section{References}

Ali Zainuddin A, Md Nor N, Md Yusof S, Irawati A, Ibrahim N, Aris T \& Huat FL (2019). Underreporting of energy and nutrient intake is a persistent issue in the Malaysian Adults Nutrition Surveys. Mal J Nutr 25:261-271.

Bleich SN \& Wang YC (2011). Consumption of sugar-sweetened beverages among adults with type 2 diabetes. Diabetes Care 34:551-555.

Bozeman SR, Hoaglin DC, Burton TM, Pashos CL, Ben-Joseph R \& Hollenbeak CS (2012). Predicting waist circumference from body mass index. BMC Med Res Methodol 12(115).

Burkhauser RV \& Cawley J (2008). Beyond BMI: The value of more accurate measures of fatness and obesity in social science research. J Health Econ 27:519-529.

Cawley J \& Meyerhoefer C (2012). The medical care costs of obesity: An instrumental variables approach. J Health Econ 31:219-230.

Cheah YK, Abdul Adzis A, Abu Bakar J \& Applanaidu SD (2019a). Factors associated with consumption of sugar-sweetened foods and beverages in Malaysia: An ethnic comparison. Int $J$ Diabetes Dev Countr 39:568578 .
Cheah YK, Abdul Adzis A, Abu Bakar J \& Applanaidu SD (2019b). Factors associated with demand for tobacco across Malaysia regions: Participation and level of consumption. Int J Bus Soc 20:1160-1177.

Cheah YK, Abdul Adzis A, Abu Bakar J \& Applanaidu SD (2020). Sociodemographic determinants of Malaysian household's use of and expenditure on alcohol: A regional comparison. Drug-Educ Prev Polic 27:165-172.

Chinedu SN, Ogunlana OO, Azuh DE, Iweala $\mathrm{EEJ}$, Afolabi IS, Uhuegbu $\mathrm{CC}$, Idachaba $\mathrm{ME}$ \& Osamor VC (2013). Correlation between body mass index and waist circumference in Nigerian adults: Implication as indicators of health status. J Public Health Res 2:93-98.

Friis K, Lyng JI, Lasgaard M \& Larsen FB (2014). Energy drink consumption and the relation to socio-demographic factors and health behaviour among young adults in Denmark. A population-based study. Eur J Public Health 24: 840-844.

Gierach M, Gierach J, Ewertowska M, Arndt A \& Junik R (2014). Correlation between body mass index and waist circumference in patients with metabolic syndrome. ISRN Endocrinol 2014:514589.

$\mathrm{Hu}$ FB (2013). Resolved: There is sufficient scientific evidence that decreasing sugarsweetened beverage consumption will reduce the prevalence of obesity and obesity-related diseases. Obes Rev 14:606-619.

IPH (2014). National Health and Morbidity Survey 2014: Malaysian Adult Nutrition Survey (MANS). Institute for Public Health, Ministry of Health Malaysia, Putrajaya.

IPH (2015). National Health and Morbidity Survey 2015: Non-communicable Diseases, Risk Factors and Other Health Problems. Institute for Public Health, Ministry of Health Malaysia, Putrajaya.

IPH (2008). The Third National Health and Morbidity Survey 2006. Institute for Public Health, Ministry of Health Malaysia, Putrajaya.

Janssen I, Katzmarzyk PT, Ross R (2004). Waist circumference and not body mass index explains obesity-related healtn risk. Am J Clin Nutr 79:379-384.

Kenkel DS, Schmeiser MD \& Urban C (2014). Is smoking inferior? Evidence from variation in the earned income tax credit. J Human Res 49:1094-1120.

Kinge JM (2017). Waist circumference, body mass index, and employment outcomes. Eur J Health Econ 18:787-799. 
Kleiman S, Ng SW \& Popkin B (2012). Drinking to our health: Can beverage companies cut calories while maintaining profits? Obesity Reviews 13:258-274.

Komlos J, Smith PK \& Bogin B (2004). Obesity and the rate of time preference: Is there a connection? J Biosoc Sci 36:209-219.

Kragelund C \& Omland T (2005). A farewell to body-mass index? Lancet 5:1589-1591.

Lin S, Tukana I, Linhart C, Morrell S, Taylor R, Vatucawaga P, Magliano DJ \& Zimmet $\mathrm{P}$ (2016). Diabetes and obesity trends in Fiji over 30 years. $J$ Diabetes 8:533-543.

Lum M (2018). The plague of NCDs afflicting Malaysia. From https://www.thestar.com. my / lifes tyle / health / 2018/10/10/noncommunicable-diseases-malaysia. [Retrieved February 12, 2020].

Mehta PD (2015). Control variables in research. In NJ Smelser and PB Balter (eds). International Encyclopedia of the Social and Behavioral Sciences, 2nd ed, volume 4 (pp. 840-843). Elsevier, Amsterdam.

Moore LL, Bradlee ML, Singer MR, Splansky GL, Proctor MH, Ellison RC \& Kreger BE (2004). BMI and waist circumference as predictors of lifetime colon cancer risk in Framingham Study adults. Int $J$ Obes 28:559-567.

Naughton P, McCarthy M \& McCarthy S (2017). Reducing consumption of confectionery foods: A post-hoc segmentation analysis using a social cognition approach. Appetite 117:168178.

O'Neil D (2015). Measuring obesity in the absence of a gold standard. Econ Hum Biol 17:116-128.

Park S, Thompson FE, McGuire LC, Pan L, Galuska DA \& Blanck HM (2016). Sociodemographic and behavioral factors associated with added sugars intake among US adults. J Acad Nutr Diet 116:1589-1598.

Pollard CM, Meng X, Hendrie GA, Hendrie D, Sullivan D, Pratt IS, Kerr DA \& Scott JA (2016). Obesity, socio-demographic and attitudinal factors associated with sugar-sweetened beverage consumption: Australian evidence. Aust NZ J Public Health 40:71-77.

Rehm CD, Matte TD, Wye GV, Young C \& Frieden TR (2008). Demographic and behavioural factors associated with daily sugar-sweetened soda consumption in New York city adults. $J$ Urban Health 85:375-385.

Smith PK, Bogin B \& Bishai D (2005). Are time preference and body mass index associated? Evidence from the National Longitudinal Survey of Youth. Econ Hum Biol 3:259-270.
Stem D, Middaugh N, Rice MS, Laden F, LopezRidaura R, Rosner B, Willett W \& Lajous M (2017). Changes in sugar-sweetened soda consumption, weight, and waist circumference: 2-year cohort of Mexican women. Am J Public Health 107:1801-1808.

Wan Mohamud WN, Musa KI, Md Khir AS, Ismail AS, Ismail IS, Abdul Kadir K, Kamaruddin NA, Yaacob NA, Mustafa N, Ali O, Md Isa SH \& Wan Bebakar WM (2011). Prevalence of overweight and obesity among adult Malaysians: An update. Asia Pac J Clin Nutr 20:35-41.

Wooldridge J (2013). Introductory econometrics: A modern approach, 5th ed. South-Western Cengage Learning, Ohio.

WHO (2018). Fact sheet: Noncommunicable diseases. World Health Organization. From https: / / www.who.int/news-room/factsheets/detail/noncommunicable-diseases [Retrieved February 12, 2020].

Xu F, Park S \& Siegel KR (2018). Factors associated with frequency of sugar-sweetened beverage consumption among US adults with diabetes or prediabetes. Am J Health Promot 32:14891497.

Yusuf S, Hawken S, Ounpuu S, Bautista L, Franzosi MG, Commerford P, Lang CC, Rumboldt Z, Onen CL, Lisheng L, Tanomsup S, Wangai P, Razak F, Sharma AM \& Anand SS (2005). Obesity and the risk of myocardial infarction in 27000 participants from 52 countries: A casecontrol study. Lancet 366:1640-1649.

Zhu Q, Shen F, Ye T, Zhou Q, Deng H \& Gu X (2014). Waist-to-height ratio is an appropriate index for identifying cardiometabolic risk in Chinese individuals with normal body mass index and waist circumference. $J$ Diabetes 6(6):527-534.

Zhu SK, Wang ZM, Heshka S, Heo M, Faith MS \& Heymsfield SB (2002). Waist circumference and obesity-associated risk factors among whites in the third National Health and Nutrition Examination Survey: clinical action thresholds. Am J Clin Nutr 76:743-749.

Zytnick D, Park S, Onufrak SJ, Kingsley BS \& Sherry B (2015). Knowledge of sugar content of sport drinks is not associated with sports drink consumption. Am J Health Promot 30:101-108. 